\title{
Factors influencing European GPs' engagement in smoking cessation: a multi-country literature review
}

\author{
Martine Stead, Kathryn Angus, Ingrid Holme, David Cohen, Gayle Tait \\ and the PESCE European Research Team
}

\begin{abstract}
Background

Smoking cessation advice by GPs is an effective and cost-effective intervention, but is not implemented as widely as it could be.

Aim

This wide-ranging Europe-wide literature review, part of the European Union (EU) PESCE (General Practitioners and the Economics of Smoking Cessation in Europe) project, explored the extent of GPs' engagement in smoking cessation and the factors that influence their engagement.

Method

Two searches were conducted, one for grey literature, across all European countries, and one for academic studies. Data from eligible studies published from 1990 onwards were synthesised and reported under four categories of influencing factors: GP characteristics, patient characteristics, structural factors, and cessation-specific knowledge and skills.

Results

The literature showed that most GPs in Europe question the smoking status of all new patients but fewer routinely ask this of regular patients, or advise smokers to quit. The proportion offering intensive interventions or prescribing treatments is lower still. Factors influencing GPs' engagement in smoking cessation include GPs' own smoking status and their attitudes towards giving smoking cessation advice; whether patients present with smoking-related symptoms, are pregnant, or heavy smokers; time, training, and reimbursement are important structural factors; and some GPs lack knowledge and skills regarding the use of specific cessation methods and treatments, or have limited awareness of specialist cessation services. No single factor or category of factors explains the variations in GPs' engagement in smoking cessation.

Conclusion

Strategies to improve the frequency and quality of GPs' engagement in smoking cessation need to address the multifaceted influences on GPs' practice and to reflect the widely differing contexts across Europe.

\section{Keywords}

attitude of health personnel; Europe; health care delivery; review literature; smoking cessation.
\end{abstract}

\section{INTRODUCTION}

Brief advice by GPs is a relatively simple smoking cessation intervention. The recent NICE (National Institute for Health and Clinical Excellence, UK) review finds strong evidence that smoking cessation interventions by GPs are both effective and costeffective in terms of patient smoking outcomes. ${ }^{1}$ The clear message from the NICE evidence is that if GPs engage more frequently in smoking cessation activity, there will be significant reductions in smoking prevalence, and associated reductions in mortality and morbidity. However, a gap persists between evidencebased recommendations for smoking cessation and actual GP behaviour across Europe. ${ }^{2}$ A better understanding is needed of why this gap persists and how it can be narrowed.

As part of the PESCE (General Practitioners and the Economics of Smoking Cessation in Europe) project, the extent to which European GPs currently engage in smoking cessation, and the factors and barriers that influence their engagement in smoking cessation activity were reviewed. A second part of the PESCE project reviewed the nature of impact of interventions that have sought to improve their engagement, ${ }^{3}$ while a third study examined the costs of measures to increase GP engagement and the resulting health and economic

M Stead, BA(Hons), deputy director; K Angus; editorial assistant; I Holme; PhD, BSc(Hons), research assistant; G Tait, BA(Hons), research coordinator, Institute for Social Marketing of Centre for Tobacco Control Research, University of Stirling and The Open University; D Cohen, BCom, MPhil, professor of health economics, Health Economics and Policy Research Unit, Faculty of Health, University of Glamorgan, Pontypridd.

Address for correspondence

Ms Martine Stead, Institute for Social Marketing, University of Stirling and The Open University, Stirling, FK9 4LA.

E-mail: martine.stead@stir.ac.uk

Submitted: 16 September 2008; Editor's response: 11 November 2008; final acceptance: 6 February 2009.

(c)British Journal of General Practice.

This article was originally online first on 11 Aug 2009. Cite this article as: Br J Gen Pract 2009; 59: 682-690. Advance online publication. DOI: 10.3399/bjgp09X454007 
benefits of reductions in patient smoking. ${ }^{4}$ The review reported here sought to cover all 29 countries (EU27, Norway and Switzerland) and to include both grey and academic literature, in an effort to generate as full a picture as possible of the influences on GP engagement in smoking cessation.

\section{METHOD}

Two search strategies were developed, for the academic and the grey literature.

\section{Academic literature}

Five electronic academic literature databases (CINAHL, The Cochrane Library, MEDLINE, PsycINFO, and Zetoc) were searched, using a combination of free text search terms, database subject headings and MeSH terms (including 'general practitioner\$', 'GP\$', 'doctor\$', 'physician\$', 'smok\$', 'cessation', 'tobacco'). Database searches were run between 22 and 26 June 2007. Results were downloaded into Reference Manager ${ }^{\circledR}$ (version 11) bibliographic software, where anything published prior to 1990 and duplicates were deleted. The cut-off point of 1990 was selected to ensure that a sufficiently large number of articles would be found and that they would be relatively up to date. The minimum requirement for non-English papers was that the title and/or abstract had to be translated into English in the bibliographic database. Further academic references were located during the grey literature searches. Papers were assessed for relevance by title and abstract initially, or using the full text where necessary, according to the criteria described below.

\section{Grey literature}

Researchers in each country searched for grey literature in their home language using a common search protocol. The protocol required searches of websites, databases, and catalogues using the same search terms as the academic searches, and relevant people and organisations to be contacted for noncommercially published or other 'grey' literature. Searches were run between November 2006 and February 2007. Literature was required to be from 1990 onwards and to meet the criteria as discussed next.

To be included in the review of factors, studies needed either to report the extent to which GPs engage in smoking cessation activity or explore factors, of any sort, influencing this engagement. The author defined engagement in smoking cessation as any kind of intervention, including raising the topic, providing information or advice, brief intervention, counselling, referral to specialist cessation services, and prescribing pharmacological treatment. Studies that correlated the relationship between a particular factor (for example, whether GPs had received training,

\section{How this fits in}

The review brings together for the first time literature from across Europe on the barriers to GP engagement in smoking cessation. No single factor explains why GPs are not always fully engaged in this area. Lack of time, reimbursement, and structural recognition of the importance of prevention activities are important, as are GPs' own attitudes, knowledge, and skills, and, in some countries, their own smoking behaviour. Solutions will need to be multifaceted and country specific.

whether GPs smoked) and their provision of smoking cessation advice were eligible, as were studies that explored GPs' own perceptions of salient issues that constrained or facilitated their engagement. Qualitative studies were included as well as quantitative, but discussion and think pieces that did not report any original research were excluded; no other methodological quality criteria were applied. This was to ensure that the pool of included literature was as large and as widely spread across the participating countries as possible. This resulted in the inclusion of studies of variable quality and studies whose quality was difficult to ascertain from the information provided.

Data on year, country, study focus, methods, results, and types of factors studied were extracted from individual papers and entered into standard spreadsheets. Local researchers completed the data extraction for the grey literature, in English, while three of the authors undertook the data extraction for the academic literature.

Data extraction entries were coded according to a typology that identified four groups of influencing factors: GP characteristics, patient characteristics, structural factors, and cessation-specific knowledge and skills (Figure 1). In view of the diversity of the studies, quantitative analysis was not appropriate, and the analysis involved a qualitative synthesis of extracted data.

\section{RESULTS}

Search record sheets were returned by 24 of the 29 PESCE project countries. Of the remaining countries, two were unable to recruit a local researcher (Estonia and Latvia) and three had recruited a local researcher but were unable to return the search record sheets (Cyprus, Luxembourg, and Spain). Five of the 24 returning countries found no eligible literature (Finland, Iceland, Lithuania, Poland, and Portugal). Dataextraction sheets were completed for studies from the remaining 19 countries.

In the included literature, the majority of studies used postal surveys to gather data, sent either to random samples of GPs or to all the GPs in a particular country or region. A number of studies used telephone interviews and very small numbers of studies videotaped consultations, ran focus groups with GPs, 
Figure 1. Typology of influencing factors

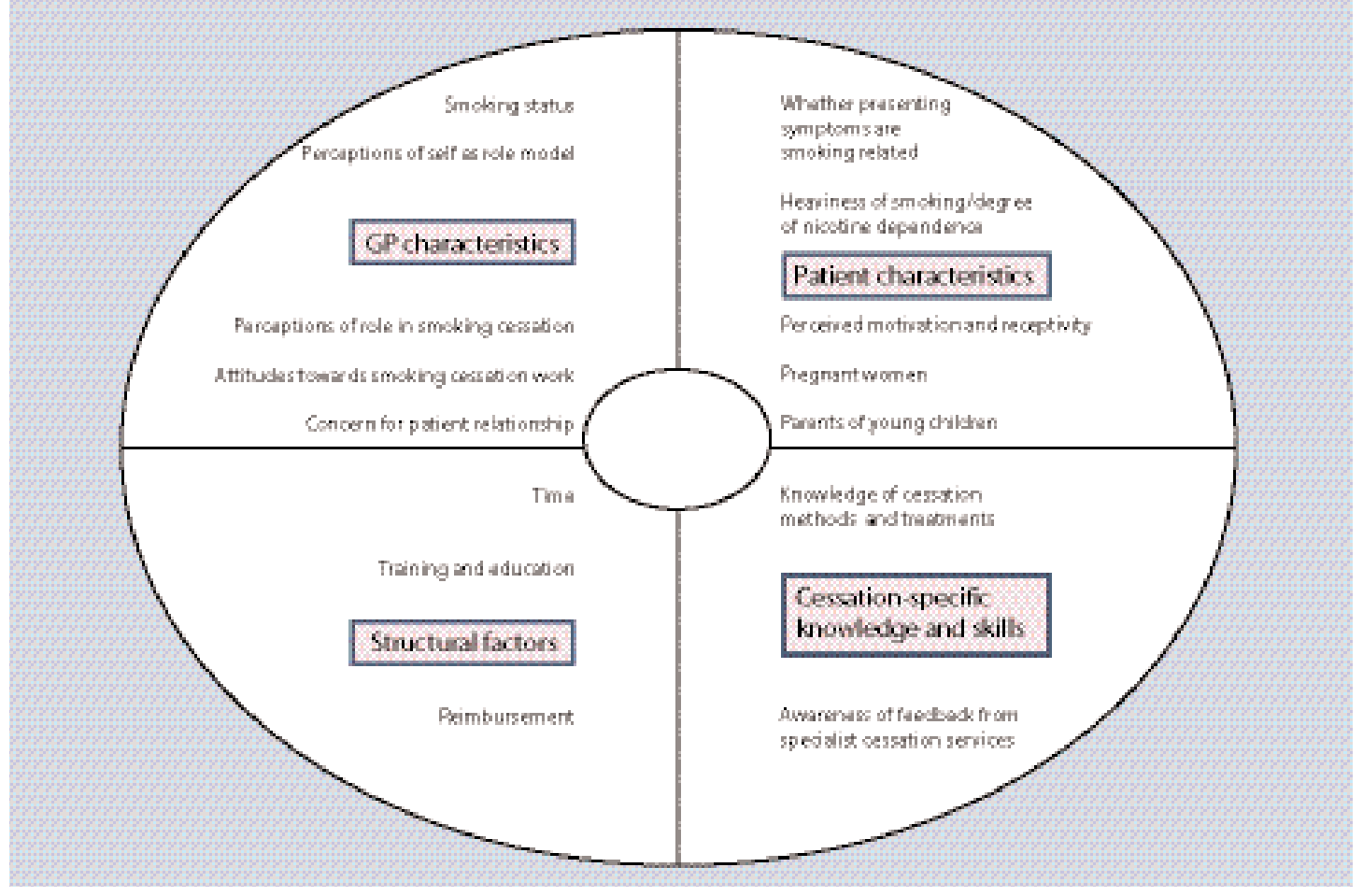

or analysed patient records and databases. Most studies used GPs as the only subject, while a small number included other health professionals such as cardiologists, lung physicians, oncologists, and practice nurses. Very few studies used a longitudinal design, and there was a small number of literature reviews. Eight studies covered more than one country in Europe. The vast majority of the included literature relied on GP or patient report as the main measure of GP engagement in smoking cessation.

Two hundred and five relevant articles (100 academic and 105 grey), reporting on 188 different studies, were eligible and were included in the review. Only those referred to directly are referenced in this paper, but a full bibliography is available from the authors.

\section{Extent to which GPs in Europe engage in smoking cessation}

All of the evidence included on the extent of GPs' cessation advice provision relies on patient or GP recall, rather than direct observation, a method which may yield more reliable results (although even observation can be problematic). ${ }^{5}$ How advice provision is defined can vary across studies and be differently interpreted by responders. Furthermore, patient recall and GP recall measures may themselves produce different results, with GPs tending to report higher levels of advice giving than patients. ${ }^{6-10}$ Importantly, because of differences in study methods, sampling, measures, and the year in which studies were conducted, results should be treated with caution and not seen as directly comparable. Findings also need to be understood in their particular country context. For example, what may seem a high level of if guidelines in that country require GPs routinely to perform a certain level of activity, and vice versa.

Overall, the evidence suggests that the majority of GPs, according to their own reporting, question all new patients as to their smoking status, with studies reporting figures between $62 \%$ and $98 \% .{ }^{6,9,11}$ Fewer GPs report routinely asking all regular patients if they smoke and routinely advising all patients to quit, even in countries where this population-based approach is recommended. For example, self-reported rates for asking about all patients' smoking status, where these have been measured, range from $28 \%$ in Belgium ${ }^{12}$ to $63 \%$ in England; $647 \%$ of GPs in Ireland are reported as 'often' raising the issue but only $1 \%$ as 'always' doing so. ${ }^{9}$ A multicentre study across 12 European countries found that, overall, only $36 \%$ of health professionals reported always advising patients to quit smoking. ${ }^{13}$

The proportion of GPs reporting offering more intensive interventions or prescribing treatments for cessation is generally lower still, and again also differs across and within countries. These variations are likely to reflect a number of factors, including availability of different support and treatment options, national policy and guidelines, and patient interest and demand. For example, Norwegian GPs in 2002 reported that they would offer bupropion (52\%), provide self-help advice (32\%), suggest a help group (9\%), talk about a stop date $(9 \%)$, or refer to an expert $(5 \%)$ with a motivated advice provision in one country may not actually be so 
patient. ${ }^{14}$ Personal counselling was the most common form of assistance (mentioned by $82 \%$ of GPs) reported in a German study, followed by nicotine replacement therapy (NRT) prescription (62\%) and bupropion $(51 \%),{ }^{15}$ while in a UK study, commonly reported forms of intervention were giving out leaflets (57\%), providing counselling (41\%), and referral to the practice nurse $(41 \%){ }^{16}$

Given that GP self-report may overestimate the amount of advice giving, it is possible that actual levels of smoking cessation advice and interventions across Europe may be lower than reported in the literature.

\section{Factors influencing GPs' engagement in smoking cessation}

As noted above, a fourfold typology of influencing factors was identified: GP characteristics, patient characteristics, structural factors, and cessationspecific knowledge and skills. Findings are reported under these four themes.

GP characteristics. A large number of studies, mostly based on questionnaires with GPs or analysis of treatment records, explore the relationship between GP characteristics and their provision of smoking cessation advice. Research has tended to focus on two main issues, GPs' own smoking status and their attitudes towards giving smoking cessation advice, including the extent to which they feel it is part of their job, are comfortable about doing so, believe that it can be effective, and perceive it as harmful to the doctor-patient relationship. Once again, the vast majority of studies rely on GP and patient report of smoking cessation activity and smoking status.

GP smoking status. Smoking prevalence by GPs in Europe varies widely across countries. Comparisons should be treated with caution because studies are from different years and use different samples, methods, and questions for establishing smoking status. High smoking prevalence rates by doctors were found in some studies: $48.5 \%$ in Slovakia, ${ }^{2}$ and $44.2 \%$ in Bulgaria, ${ }^{17}$ for example, both in 2005. This contrasts with, for example, Estonia, Finland, Germany, Slovenia, Sweden, England, and Wales, where studies reported regular smoking by $10 \%$ or fewer GPs.

Grey literature studies suggest that around one-third of Bulgarian and Greek GPs have smoked in front of their patients, ${ }^{17,18}$ which implies that some GPs do not necessarily see themselves as exemplars to their patients in terms of their own health behaviour. Although some studies find that GPs generally regard themselves as role models, ${ }^{19}$ evidence from several countries reports that doctors who smoke do not subscribe as fully to this view. ${ }^{11,12,20}$

Generally, studies found that GPs who smoke report giving cessation advice less frequently than nonsmoking GPs, although not all studies supported this pattern. Studies in Austria, ${ }^{21}$ Finland, ${ }^{22}$ France, ${ }^{23,24}$ and Greece $^{25}$ all found that non-smoking GPs were significantly more likely than smoking GPs to report that they raised the issue or advise quitting. However, a recent comparative study of 11 European Union (EU) countries concluded that while GPs who smoke tended to be less frequent in advising quitting, the difference was not significant. ${ }^{2}$ Similarly, a German study reported that GPs' smoking status did not affect the extent to which they reported counselling patients regarding smoking cessation. ${ }^{26}$

A small number of studies have examined the relationship between GPs' own smoking status and patient smoking outcomes. One Norwegian study showed that pregnant women whose GPs were smokers had higher daily cigarette consumption (based on patient self-report and serum thiocyanate tests) than women who attended non-smoking GPs. ${ }^{27}$ However, a French cessation intervention study suggested that once GPs who smoke were involved in smoking cessation, their own smoking-related attitudes and behaviour did not influence their effectiveness in terms of patients' self-reported quit rates. ${ }^{28}$

GP attitudes towards giving smoking cessation advice. Generally, studies find that GPs regard smoking cessation as an important preventive task, and one in which they can make a difference. ${ }^{29,30}$ However, for some GPs, advice concerning lifestyle appears to fall outside the traditional sphere of general practice. Evidence from some Scandinavian studies suggests that a sizeable minority of GPs do not regard discussing smoking habits, informing patients of the health risks, and assisting patients to quit as part of their role. ${ }^{31,32}$ There are signs of change in this area: only $9 \%$ of GPs in Norway did not consider it their job to discuss patients' smoking habits in a 2002 study, ${ }^{14}$ compared with $29 \%$ in $1999 .{ }^{32}$ This may reflect shifts in norms attributable to increasing national tobacco control policies after 1999, or differences in the studies' methodologies.

The skills and attitudes involved in providing health promotion and prevention may for some GPs lie outside their professional comfort zone. Thus, between $14 \%$ and $43 \%$ of Scandinavian GPs listed 'feeling uncomfortable giving information on the subject' as a barrier to giving smoking cessation advice. ${ }^{32}$ However, a study from Norway found that the number of GPs who thought it was embarrassing to ask people about their smoking habits nearly halved between 1999 and $2001 .{ }^{14}$ There are also indications that some GPs find cessation work unenjoyable and unrewarding. For example, an English study found that only $35 \%$ of GPs said they enjoyed smoking cessation counselling, with 
$38 \%$ finding it difficult. ${ }^{33}$ However, in another study, where $85 \%$ of GPs reported feeling they were effective in persuading some patients to stop, $61 \%$ reported finding discussing smoking rewarding. ${ }^{34}$ Grey literature studies support the view that many GPs perceive smoking cessation work as unrewarding and not meriting the effort put into it. ${ }^{10,35}$

One factor influencing some GPs' willingness to raise the topic of smoking is concern for the GP-patient relationship. A study in England found that the belief that giving cessation advice might jeopardise the patient relationship was significantly associated with a lower frequency of giving advice, ${ }^{36}$ and another study reported that this was a particular concern with pregnant smokers (both based on GP self-report). ${ }^{33}$ Similarly, in a study in Ireland, some GPs expressed the view that smoking advice could potentially damage the doctor-patient relationship, particularly with older or terminally ill patients where it would make little material difference to their health ${ }^{37} \mathrm{~A}$ comparative study carried out in Sweden and Slovenia found that GPs' concerns about patient self-determination and rights and a desire to avoid extreme anti-smoking positions were associated with GP reluctance to raise the topic of smoking when presented with different hypothetical patient consultation scenarios. ${ }^{38}$

No consistent associations were found in the review between GP demographic characteristics - age and sex - and extent of engagement in smoking cessation.

\section{Patient characteristics}

Patient characteristics also have an influence on GPs' likelihood of raising the issue of cessation and offering intervention. Again, the included literature on this theme relies solely on GP report of smoking cessation activity.

Generally, GPs are more likely to report giving cessation advice where patients present with smokingrelated symptoms. For example, in an Austrian survey, $50 \%$ of GPs reported asking all patients their smoking history, but this rose to $98 \%$ where the patient had smoking-related symptoms. ${ }^{21}$ A similar pattern was found in a Belgian study, in which $28 \%$ of GPs said they would routinely assess smoking in all patients, rising to $85 \%$ in patients with smoking-related disease. ${ }^{12} \mathrm{~A}$ survey of 194 Dutch GPs found that while only $60 \%$ reported giving stop smoking advice no matter what the conditions, $98 \%$ would offer such advice when it was seen as a risk factor to the patient's complaint. ${ }^{39}$ In one UK study, $97 \%$ of GPs thought their advice was more effective when linked to a patient's presenting problem, and $65 \%$ reported that linking their anti-smoking advice to the presenting complaint was one of their three most preferred approaches to discussing smoking. ${ }^{34}$ This suggests that GPs select patients whom they consider more likely to be open to smoking advice. Qualitative studies suggest that GPs' perceptions of patients' receptivity and motivation are important influences on the decision whether or not to advise quitting. ${ }^{40}$

Several studies suggest that GPs are more likely to report that they intervene with heavy smokers than light smokers. ${ }^{41-43}$ Not all studies suggest a greater tendency to advise heavy than light smokers, however, ${ }^{44}$ and there is some evidence to suggest that a number of GPs have difficulty with recognising smoking status and level of addiction. ${ }^{42}$

Guidelines in many countries suggest that smoking cessation should be raised with pregnant mothers, and this is reflected in practice, with $91 \%$ of Scottish GPs, ${ }^{45}$ and $94 \%$ of Dutch GPs $^{39}$ reporting in studies that they would discuss smoking cessation with this group. However, a study of English health professionals including GPs found that several had reservations about doing so, due to not wanting to cause guilt or anxiety among pregnant women, ${ }^{33}$ and there also appears to be a lack of awareness regarding the safety of prescribing NRT during pregnancy. ${ }^{46}$ Although parents who have young children are also identified in guidelines as a priority target, the review suggests that GPs may pay this group less attention. For example, a German study of paediatricians (including but not limited to GPs) found that only $26 \%$ of doctors reported asking if parents smoked, and only $47 \%$ of these noted this in the patient record. ${ }^{47}$

\section{Structural factors}

Three structural factors emerged as important in the review: time, training, and reimbursement.

Time. Studies suggest that many GPs perceive time as a major barrier to smoking cessation intervention. The proportions of GPs reporting that they are constrained from giving cessation advice by lack of time range from $74 \%$ in a study in Italy ${ }^{48}$ to $32 \%$ in an Irish study. ${ }^{9}$ No studies were found that correlated the actual consultation time available to GPs with their likelihood of giving cessation advice.

Training. Several studies report an association between GPs' participation in specialist training and their reported level of engagement in smoking cessation. For example, a German study found that receipt of training was significantly inversely associated with a self-reported low level of cessation activity, ${ }^{15}$ while a large study of doctors (including GPs) in Belgium found that doctors who were trained in smoking issues reported assessing patients' stage of change more frequently than non-trained doctors, and were also more likely to report prescribing NRT. ${ }^{12}$ Similarly, a Swedish study found that GPs who had received training/education in cessation reported higher levels than untrained doctors of cessation activities such as 
offering self-help material, offering follow-up support at a clinic, discussing a quit date, and advising NRT. ${ }^{31}$ An Irish study reported an association between participation in smoking cessation training and referrals to the cessation services. ${ }^{9}$ However, one UK study found that while $28 \%$ of GPs reported having received training, no differences were found between trained and untrained GPs in the frequency of assistance they subsequently reported giving to patients, suggesting that provision of training alone may not be sufficient to influence routine practice. ${ }^{16}$

Levels of participation in smoking cessation training by GPs are variable but generally low, with studies reporting that only around one-tenth to one-third of GPs have received any postgraduate education or training in smoking cessation. ${ }^{9,12,49}$ Although it was not part of the review's remit to examine the extent of training provision, some included studies also reported this. For example, a UK study of newly qualified doctors noted that the great majority of UK medical graduates receive little or no cessation training, and that this is a Europe-wide problem. ${ }^{50} \mathrm{~A}$ sizeable proportion of GPs report that they would welcome further training or qualifications in cessation, in studies from a range of countries including Italy, ${ }^{51}$ Bulgaria, ${ }^{17}$ and Ireland. ${ }^{9}$

Cost and reimbursement. Several studies have examined whether GPs feel that lack of reimbursement is a deterrent to providing smoking cessation advice, or whether they would feel more motivated to provide cessation advice if reimbursement were offered. The results are mixed. A study across several European countries found that, on average, $40 \%$ gave lack of reimbursement as a reason for not undertaking health promotion, ${ }^{2}$ but the proportions varied widely from country to country: from $7 \%$ in Spain to $64 \%$ in Croatia. $^{2}$ Of two studies in Germany, one found that only $6 \%$ of paediatricians (including GPs) cited lack of reimbursement as a reason for not providing smoking cessation advice, ${ }^{47}$ while in the other, $37-40 \%$ of GPs agreed that inadequate reimbursement was a barrier to providing smoking cessation interventions. ${ }^{15}$ A grey literature study in the Czech Republic reported that GPs would be interested in providing a smoking cessation clinic on condition it was paid for by patients. ${ }^{52}$ Overall, the review suggests that there are substantial differences between European GPs in their attitudes towards reimbursement for smoking cessation.

Evidence from the UK, using a large dataset and tracking GP activity over 15 years, found that offering 'quality payments' for the ascertainment and recording of patient smoking status and the recording of smoking cessation advice increased the frequency with which GPs did both of these, based on analysis of patient data. $^{53}$ The long time frame, large sample, and use of patient records made this the most robust study of the review. However, other policy changes occurred over the same period, which may have contributed to this increased activity (for example, the increased availability of local cessation services to which GPs could refer patients), making it difficult to isolate the effect of reimbursement changes alone. Payments that are linked to individual patient outcomes - for example, $€ x$ per successful quitter - do not appear to be associated with increased provision of cessation advice (based on patient recall and GP self-report). ${ }^{54,55}$ It is possible that such payment schemes may encourage data manipulation and tokenistic activity. There is evidence from patient and prescription data that reducing or removing the cost of pharmacological treatments for cessation can increase GPs' prescribing or recommending of such treatments, ${ }^{53,56}$ although some GPs are ambivalent about recommending NRT products. $^{57,58}$

\section{Cessation-specific knowledge and skills}

Finally, the review suggests that some GPs lack knowledge and skills regarding the use of specific cessation methods and treatments and have limited awareness of specialist cessation services.

A study in Italy reported that $81 \%$ of GPs said they were not aware of smoking cessation techniques based on counselling or did not regard them as effective, and only $22 \%$ considered themselves adequately informed about NRT. ${ }^{48}$ Similarly, there is evidence that GPs both underestimate and overestimate recommended dosages of $\mathrm{NRT},{ }^{59}$ and lack confidence about discussing and prescribing it, both generally ${ }^{50}$ and in pregnancy. ${ }^{46}$ Studies suggest that some GPs feel they do not have the skills to provide cessation counselling and other techniques. ${ }^{33,50}$ However, a UK study published in 2006 suggests that there is continual improvement: examining the extent to which GPs follow guidelines concerning the prescription of NRT and bupropion, the study found that the length of time for which patients were advised to take the treatment (as recalled by patients) was broadly in line with guidelines, as were other aspects such as dosage and timing..$^{60}$

The review also suggests that GPs' willingness to refer patients for specialist cessation help is related to their knowledge of such specialist services, as well as to their availability. Two studies suggest that GPs are not completely familiar with local smoking cessation services. ${ }^{6,9}$ This lack of familiarity, coupled with limited feedback from both smoking cessation services and patients regarding the progress made by referrals to the service, may inhibit more frequent use of smoking cessation services. Fifty-eight per cent of GPs in a UK study reported that the existence of local smoking cessation services had made it easier to raise the issue 
of smoking with patients, and $41 \%$ thought it had led to them increasing the number of patients they advised to stop smoking. ${ }^{6}$

\section{DISCUSSION}

This review represents the first attempt to bring together literature from across Europe on the extent to which GPs currently engage in smoking cessation interventions and the factors that facilitate and hinder this engagement. It shows that although many GPs do report asking about patients' smoking status and advise smokers to quit, the level of activity is variable across countries and often below what has been recommended by bodies such as the World Health Organization (WHO), ${ }^{61} \mathrm{NICE},{ }^{1}$ Royal College of Physicians, ${ }^{62}$ and WHO Europe. ${ }^{63}$

One clear message from the review is that no single factor or category of factors explains the variability in GPs' engagement in smoking cessation interventions; therefore, solutions for influencing GP behaviour will need to be similarly multifaceted..$^{64,65}$ Overcoming time and cost barriers remains important, ${ }^{2}$ but these are not the only or primary barriers. GPs' knowledge, skills, and attitudes - including whether GPs personally find such work rewarding and feel it can make a difference - are also important.

Training emerges as a priority issue, with several studies showing that participation in training correlates with increased engagement in smoking cessation activity, and indicating that a large proportion of GPs would welcome continuing education in this area. The review findings suggest that smoking cessation should be included in postgraduate training for all GPs in Europe. However, training alone may not be sufficient to overcome all the barriers to providing cessation advice in routine practice, such as competing time demands or lack of system-wide recognition of the importance of such activity. ${ }^{66}$ Contrary to some prevailing wisdom, lack of reimbursement did not emerge as the most salient barrier from GPs' own perspective, with the review finding varying levels of importance attached to this factor in different countries. Studies in other countries have similarly found that cost is not a major barrier. ${ }^{67}$ Nonetheless, UK evidence suggests that when preventive activity is financially recognised, in conjunction with improved options for prescribing and referral to specialist services, this can lead to sustained changes in smoking cessation activity.

Although strategies to overcome the barriers to increased engagement will need to be multifaceted, the review does suggest that some factors are more important in some countries than others. Helping the relatively high proportion of GPs who smoke to quit should be a priority for some countries, as this is likely to encourage more positive attitudes towards and increased engagement in smoking cessation activity, as well as being an important preventive measure in its own right. GPs quitting also helps to send a signal to patients about the social undesirability of smoking. In some countries it will be important to tackle the perception that advising about smoking cessation is a peripheral or unimportant part of the GP's role. In other countries, the major challenge will be to help committed GPs put their interest in smoking cessation into practice through providing more specialist training, easing time pressures, or developing systems for building cessation activity into routine practice. ${ }^{68}$ Providing more feedback to GPs on the effectiveness of cessation techniques in general and on individual patients' quitting success, may help overcome the perception that this type of work is unenjoyable and difficult. Making it obligatory in all countries to record patients' smoking status and related activity should help integrate smoking cessation into routine GP practice.

\section{Strengths and limitations of the study}

The review has both strengths and limitations. It is, to the authors' knowledge, the first attempt to search for an review literature from across Europe on this important issue. Given the dispersed nature of the research team, it is possible that the searches were conducted with varying degrees of thoroughness in different countries, even with the provision of detailed guidance and standard protocols. It is possible therefore that other grey literature remains unidentified. The review therefore cannot be considered exhaustive. The evidence that was found and included in the review is of variable quality. Much of it is grey, that is not published in peer-reviewed academic journals, and even the academic literature has many limitations, including self-selecting samples or small sample size, and the vast majority uses GP self-reports or patient reports as measures of GP behaviour. If self-reporting reflects what GPs think they do or should do rather than what they objectively do, ${ }^{2}$ it is possible that the picture painted here of GP practice is over-optimistic. A relatively large number of studies have explored the relationship between GP characteristics, such as their own smoking behaviour or attitudes towards engaging in cessation work, and their actual engagement in smoking cessation. Again, the validity of the evidence on this relationship is limited by the reliance on GP selfreporting as a measure of activity. Literature has also explored how patient characteristics and the context of the consultation can influence GPs' decisions as to whether or not to intervene. Several studies have identified what GPs themselves see as the salient barriers to their engagement in smoking cessation interventions. Less attention has been paid in the literature to investigating the relationship between structural factors, such as how GPs are paid and how primary care is structured, and GP engagement in 
cessation. This is an important gap, which merits further attention.

Although strenuous efforts were made to facilitate inclusion of literature from across Europe, the included evidence base is still to some extent dominated by a handful of countries. There is limited evidence from southern, eastern, and 'new' European countries. This is particularly the case with the academic literature, where the requirement for papers to have title and/or abstract translated into English in the bibliographic database meant that some studies in other languages would have been omitted.

\section{Implications for future research and clinical practice}

Social norms and policies regarding tobacco differ widely between different European countries, as do health systems, the primary care context, and cultural attitudes towards prevention and health promotion. ${ }^{2,69-73}$ Recommendations for actions arising from the review will therefore require careful adaptation to the national context.

Although the evidence from some countries is limited to handful of grey literature studies, when synthesised in this review they form a large and rich body of evidence which has wider generalisability and potential for influence. The challenge for each of the PESCE countries now is to develop country-specific strategies for better encouraging and supporting GP smoking cessation activity, building on the evidence of the review.

\section{Funding body}

The PESCE project as a whole was funded by the European Commission Public Health Programme 2003-2008 (Grant Agreement 200 5319). The literature review was part-funded by Cancer Research UK (www.cancerresearchuk.org)

\section{Ethics committee}

\section{Not applicable}

\section{Competing interests}

The authors have stated that there are none

\section{Acknowledgements}

PESCE European research team: Dr Carmen Cabezas Peña, Health Department of the Autonomous Department of Catalonia, Spain; Antonella Cardone, Consultant on Social and Public Health Issues, Italy; Professor Luke Clancy and Laura Currie, The Research Institute For a Tobacco Free Society (RIFTS), Ireland; Professor David Cohen, Dr Fasihul Alam, Dr Paul Jarvis and Dr Sam Groves, Health Economics and Policy Research Unit, University of Glamorgan, Wales; Dr Peter Csepe, Smoking or Health Hungarian Foundation, Hungary; Dr Jean Daver, President, Tabac et Liberté, France; Sibylle Fleitmann, Independent Consultant Tobacco Control, Germany; Helena Koprivnikar, National Institute of Public Health, Slovenia; Sophie Massin, CES-MATISSE, Université Paris 1, Maison des Sciences Economiques, France; Dr Ivo Nagels, Fondation contre le Cancer, Belgium; Maria Pilali, Hellenic Cancer Society, Greece; Marta Porêbiak, Health Promotion Foundation, Poland; Dr Dewi Segaar, STIVORO, The Netherlands; Dr Nicolo Seminara, European School of General Medicine (SEMG), Italy; Martine Stead and Kathryn Angus, Centre for Tobacco Control Research, University of Stirling \& the Open University, Scotland; Dr Hans Storm and Inge Haunstrup-Clemmensen, Danish Cancer Society, Denmark; Ann Van den Bruel, Katolieke Universiteit Leuven
(KUL), Belgium; Lotje Van Esch, Radboud University Medical Centre, Centre for Quality of Care Research (WOK), The Netherlands; Dr Antonio Vaz Carneiro and Dr Joao Costa, Faculty of Medicine, University of Lisbon, Portugal.

\section{Discuss this article}

Contribute and read comments about this article on the Discussion Forum: http://www.rcgp.org.uk/bjgp-discuss

\section{REFERENCES}

1. National Institute for Health and Clinical Excellence. Smoking cessation services in primary care, pharmacies, local authorities and workplaces, particularly for manual working groups, pregnant women and hard to reach communities. NICE public health guidance 10. London: NICE, 2008.

2. Brotons C, Bjorkelund C, Bulc M, et al. Prevention and health promotion in clinical practice: the views of general practitioners in Europe. Prev Med 2005; 40(5): 595-601.

3. Stead M, Angus K, Holme I, Tait G. Review of the literature on factors that facilitate and hinder use of smoking cessation interventions by GPs, and of interventions to change GP behaviour. Work Package 4 of the PESCE Project. Stirling: Centre for Tobacco Control Research, University of Stirling, 2007.

4. Cohen D, Alam F, Groves S, Jarvis P. Costs and benefits of measures to increase general practitioner advice givng with respect to smoking cessation. Work package 5 of the PESCE project. Pontypridd: Health Economics and Policy Research Unit, University of Glamorgan, 2008.

5. Coleman T, Wilson A. Anti-smoking advice from general practitioners: is a population-based approach to advice-giving feasible? Br J Gen Pract 2000; 50(461): 1001-1004

6. McEwen A, West R, Owen L, Raw M. General practitioners' views on and referral to NHS smoking cessation services. Public Health 2005; 119(4): 262-268.

7. Coleman T, Wynn A, Barrett S, Wilson A. Discussion of NRT and other antismoking interventions in UK general practitioners' routine consultations. Nicotine Tob Res 2003; 5(2): 141-144.

8. Wynn A, Coleman T, Barrett S, Wilson A. Factors associated with the provision of anti-smoking advice in general practice consultations. $\mathrm{Br} \mathrm{J}$ Gen Pract 2002; 52(485): 997-999.

9. O'Sullivan J. An evaluation of general practitioners' interactions with the smoking cessation service and the impact of a desktop resource on the service. MA thesis. Cork: University College Cork Department of Epidemiology and Public Health. National University of Ireland, 2006.

10. Rowe M. The management of smoking cessation in general practice. Dublin: The Irish College of General Practitioners, 1998.

11. Dekker HM, Looman CWN, Adriaanse HP, van der Maas PJ. Prevalence of smoking in physicians and medical students, and the generation effect in The Netherlands. Soc Sci Med 1993; 36(6): 817-822.

12. Prignot J, Bartsch P, Vermeire P, et al. Physician's involvement in the smoking cessation process of their patients. Results of a 1998 survey among 4643 Belgian physicians. Acta Clin Belg 2000; 55(5): 266-275.

13. Puska PMJ, Barrueco M, Roussos C, et al. The participation of health professionals in a smoking-cessation programme positively influences the smoking cessation advice given to patients. Int J Clin Pract 2005; 59(4): 447-452.

14. Gallefoss F, Drangsholt K. Røykeintervensjon og hindringer for dette blant fastleger i Vest-Agder. [Smoking cessation intervention and barriers against it among general practitioners in Vest-Agder county]. Tidsskr Nor Laegeforen 2002; 122(27): 2608-2611.

15. Twardella D, Brenner H. Lack of training as a central barrier to the promotion of smoking cessation: a survey among general practitioners in Germany. Eur J Public Health 2005; 15(2): 140-145.

16. McEwen A, West R. Smoking cessation activities by general practitioners and practice nurses. Tob Control 2001; 10(1): 27-32.

17. Vassilevski N, Tsolova G, Vukov M, Hinov T. Tobacco smoking among health professionals (doctors). Sofia: National Association against Smoking, Ministry of Health, National Center of Public Health Protection, Bulgarian Physicians Union and CINDI Programme, 2005.

18. Kordiolis N, Filopoulos E, Bellos G, Dontas N. Smoking habits of doctors of health centres, national survey carried out at 1995-199. Hellenic Cancer Society, 17th International Cancer Congress, 1998. In: Moraes M, Brentani $\mathrm{R}$, Bevilacqua R (eds.) Proceedings of the 17th International Cancer Congress of the International Union against Cancer (UICC), August 1998, Rio de Janeiro, Brazil. Bologna: Monduzzi, 1998: 1665-1668.

19. Bolinder G, Himmelmann L, Johansson K. Svenska läkare röker minst i världen. Ny studie av tobaksvanor och attityder till tobak. [Swedish physicians smoke least in all the world. A new study of smoking habits and attitudes to tobacco]. Lakartidningen 2002; 99(30-31):3111-3117.

20. Pärna K, Rahu K, Rahu M. Smoking habits and attitudes towards smoking among Estonian physicians. Public Health 2005; 119(5): 390-399.

21. Kössler W, Lanzenberger M, Zwick H. Smoking habits of office-based general practitioners and internists in Austria and their smoking cessation efforts. Wien Klin Wochenschr 2002; 114(17-18): 762-765. 
22. Barengo NC, Sandstrom HP, JormanainenVJ, Myllykangas MT. Attitudes and behaviours in smoking cessation among general practitioners in Finland 2001. Soz Praventivmed 2005; 50(6): 355-360.

23. Ansquer JC, Stoll L, Lagrue G. A survey of smoking among general practitioners. Impact on their attitude towards smoking in their patients. Sem Hop Paris 1992; 68(36-37): 1312.

24. Tessier J-F, Rene L, Nejiari C, et al. Attitudes and opinions of French general practitioners towards tobacco. Tob Control 1993; 2(3): 226-230

25. Sotiropoulos A, Gikas A, Spanou E, et al. Smoking habits and associated factors among Greek physicians. Public Health 2007; 121(5): 333-340.

26. Ulbricht S, Meyer C, Schumann A, et al. Provision of smoking cessation counseling by general practitioners assisted by training and screening procedure. Patient Educ Couns 2006; 63(1-2): 232-238.

27. Haug K, Fugelli P, Aaro LE, Foss OP. Is smoking intervention in general practice more successful among pregnant than non-pregnant women? Fam Pract 1994; 11(2): 111-116.

28. Slama K, Karsenty S, Hirsch A. French general practitioners' attitudes and reported practices in relation to their participation and effectiveness in a minimal smoking cessation programme for patients. Addiction 1999; 94(1): 125-132.

29. Storm HH, Clemmensen IH, Schroll B, et al. General Practitioners empowerment project (phase i report and supplement). European Commission and ENSP (European Network for Smoking Prevention). Copenhagen: The Danish Cancer Society, 2000.

30. Pieterse ME, Van Doesburgh R. Stoppen met roken in een gezondheidscentrum: samenwerking met een voorlichtingsfunctionaris: minder werk voor de huisarts met meer effect. [Stop smoking in a health centrum. Cooperation with a health visitor: less work for the GP with more effect.] Medisch Contact 1998; 53(20): 691-692.

31. Boldemann C, Gilljam H, Lund KE, Helgason AR. Smoking cessation in general practice: the effects of a quitline. Nicotine Tob Res 2006; 8(6): 785-790.

32. Helgason AR, Lund KE. General practitioners' perceived barriers to smoking cessation-results from four Nordic countries. Scand J Public Health 2002; 30(2): 141-147.

33. Clasper $\mathrm{P}$, White $\mathrm{M}$. Smoking cessation interventions in pregnancy: practice and views of midwives, GPs and obstetricians. Health Educ J 1995; 54(2): 150-162

34. Coleman T, Wilson A. Anti-smoking advice in general practice consultations: general practitioners' attitudes, reported practice and perceived problems. Br J Gen Pract 1996; 46(403): 87-91.

35. McIntyre D, Scott K. The silent treatment - why GPs and patients don't talk about smoking. A report from No Smoking Day. London: No Smoking Day, 2003.

36. McEwen A, West R, Preston A. Triggering anti-smoking advice by GPs: mode of action of an intervention stimulating smoking cessation advice by GPs. Patient Educ Couns 2006; 62(4): 89-94.

37. McCarrick E. A new approach to help smokers quit: brief interventions training for general practitioners a qualitative evaluation. Dublin: Irish College of General Practitioners and the Smoking Target Action Group, 2003.

38. Bremberg S, Nilstun T, Kovac V, Zwitter M. GPs facing reluctant and demanding patients: analysing ethical justifications. Fam Pract 2003; 20(3): 254-261.

39. Koolhaas C. Campagne 'Meer huisartsen gaan voor minder rokers'. TNS NIPO in opdracht van STIVORO. [More family clinics are needed for fewer smokers' campaign. TNS NIPO for STIVORO.] Den Haag: STIVORO, 2005.

40. Coleman T, Murphy E, Cheater F. Factors influencing discussion of smoking between general practitioners and patients who smoke: a qualitative study. Br J Gen Pract 2000; 50(452): 207-210.

41. Devroey D, Kartounian J, Vandevoorde J, et al. Primary prevention of coronary heart disease in general practice: a cross sectional population study. Int J Clin Pract 2004; 58(2): 130-138.

42. Hoch E, Muehlig S, Höffler M, et al. How prevalent is smoking and nicotine dependence in primary care in Germany? Addiction 2004; 99(12): 1586-1598.

43. Segnan N, Battista RN, Rosso S, et al. Preventive practices of genera practitioners in Torino, Italy. Am J Prev Med 1992; 8(6):333-338.

44. Donner-Banzhoff N, Kreienbrock L, Baum E. Family practitioners' intervention against smoking in Germany and the UK: does remuneration affect preventive activity? Soz Praventivmed 1996; 41(4): 224-230.

45. Lennox AS, Taylor R. Smoking cessation activity within primary health care in Scotland: present constraints and their implications. Health Educ 1995; 54: 48-60.

46. Herbert R, Coleman T, Britton J. UK general practitioners' beliefs, attitudes, and reported prescribing of nicotine replacement therapy in pregnancy. Nicotine Tob Res 2005; 7(4): 541-546.

47. Hannöver W, Thyrian JR, John U. Short report: paediatricians' attitude towards counselling parents postpartum about their smoking behaviour. Eur J Public Health 2004; 14(2): 199-200.
48. Ragazzoni P, Zotti AM, Coffano ME, et al. Medici di Medicina Generale alleati dello specialista nella lotta al tabagismo? [Are General Practitioner allied with specialists in the figth [sic] against smoking?] Monaldi Arch Ches Dis 2003; 58(3): 214-221.

49. Pizzo AM, Chellini E, Grazzini G, et al. Italian general practitioners and smoking cessation strategies. Tumori 2003; 89(3): 250-254.

50. Roddy E, Rubin P, Britton J on behalf of the Tobacco Advisory Group of the Royal College of Physicians. A study of smoking and smoking cessation on the curricula of UK medical schools. Tob Control 2004; 13(1): 74-77.

51. Pretti G, Roncarolo F, Bonfanti M, et al. Indagine conoscitiva sulle abitudini al fumo, le opinioni e l'attività di prevenzione del tabagismo tra medici di medicina generale della Lombardia. [Survey among GPs about their smoking habits, opinions and behaviours in smoking prevention in Lombardy (Northern Italy)]. Epidemiol Prev 2006; 30(6): 343-347.

52. Cupka J. Poradna pro léčbu závislosti na tabáku v ordinaci praktického lékaře. [Tobacco dependence treatment in GP's ambulance]. Praha: Společnost všeobecného lékařství ČLS JEP (General Medicine Society), 2006.

53. Coleman T, Lewis S, Hubbard R, Smith C. Impact of contractual financial incentives on the ascertainment and management of smoking in primary care. Addiction 2007; 102(5): 803-808

54. Coleman T, Wynn AT, Barrett S, et al. Intervention study to evaluate pilot health promotion payment aimed at increasing general practitioners antismoking advice to smokers. BMJ 2001; 323(7310): 435-436.

55. Coleman T, Wynn AT, Stevenson K, Cheater F. Qualitative study of pilot payment aimed at increasing general practitioners' antismoking advice to smokers. BMJ 2001; 323(7310): 432-435.

56. Tilson L, Bennett K, Barry M. Prescribing trends for nicotine replacement therapy in primary care. Ir Med J 2004; 97(9): 270-273.

57. McEwen A, West R, Owen L. General Practitioners' views on the provision of nicotine replacement therapy and bupropion. BMC Fam Pract 2001; 2: 6 .

58. McEwen A, West R, Owen L. GP prescribing of nicotine replacement and bupropion to aid smoking cessation in England and Wales. Addiction 2004; 99(11): 1470-1474.

59. Howell F, Hume D, Maher B, et al. Smoking cessation and the use of nicotine replacement therapy in general practice. Presented at the 2nd European Conference on Tobacco or Health, February, Las Palmas De Gran Canaria, Spain, February, 1999.

60. Wilson A, Sinfield P, Rodgers S, et al. Drugs to support smoking cessation in UK general practice: are evidence based guidelines being followed? Qual Saf Health Care 2006; 15(4): 284-288.

61. Raw M, Anderson P, Batra A, et al. WHO Europe evidence based recommendations on the treatment of tobacco dependence. Tob Control 2002; 11(1): 44-46.

62. Royal College of Physicians (RCP), ASH (Action on Smoking and Health) Forty fatal years. A review of the 40 years since the publication of the 1962 Report of the Royal College of Physicians. London: ASH \& RCP, 2002.

63. WHO Europe. WHO European strategy for smoking cessation policy. European Tobacco Control Policy Series, No. 1. Copenhagen: The Regional Office for Europe of the World Health Organization, 2004.

64. Green LA, Gorenflo DW, Wyszewianski L. Validating an instrument for selecting interventions to change physician practice patterns. J Fam Pract 2002; 51(11): 938-942.

65. Wyszewianski L, Green LA. Strategies for changing clinicians' practice patterns. A new perspective. J Fam Pract 2000; 49(5): 461-464.

66. Solberg LI. Incentivising, facilitating, and implementing an office tobacco cessation system. Tob Control 2000; 9 Suppl 1: i37-i41.

67. Young JM, Ward JE. Implementing guidelines for smoking cessation advice in Australian general practice: opinions, current practices, readiness to change and perceved barriers. Fam Pract 2001; 18(1): 14-20.

68. Lagarde F, Tremblay M, Des Marchais V. Physicians taking action against smoking. In: Hastings G (ed). Social marketing: why should the devil have all the best tunes. Oxford: Butterworth-Heinemann, 2007: 292-296.

69. Lionis C, Stoffers HE, Hummers-Pradier E, et al. Setting priorities and identifying barriers for general practice research in Europe. Results from an EGPRW meeting. Fam Pract 2004; 21(5): 587-593.

70. Schnohr CW, Kreiner S, Rasmussen M, et al. The role of national policies intended to regulate adolescent smoking in explaining the prevalence of daily smoking: a study of adolescents from 27 European countries. Addiction 2008; 103(1): 824-831.

71. Hassan L, Walsh G, Shiu E, et al. Modelling persuasion in social advertising: a study of responsible thinking in antismoking promotion in eight Eastern EU member states. J Advertising 2007; 36(2): 15-31.

72. Devlin E, Anderson S, Hastings GB, et al. Targeting smokers via tobacco product labelling: opportunities and challenges for Pan European health promotion. Health Promot Int 2005; 20(1): 41-49.

73. Laforge RG, Velicer WF, Levesque DA, et al. Measuring support for tobacco control policy in selected areas of six countries. Tob Control 1998; 7(3): $241-246$ 